\title{
Towards a Better Understanding of Lawyers' Judgmental Biases in Client Representation: The Role of Need for Cognitive Closure
}

\author{
James H. Stark and Maxim Milyavsky*
}

\begin{abstract}
Previous research demonstrates that lawyers and law students are, on average, prone to overconfidence bias and self-serving judgments of fairness when they take on a representative lawyering role. This is the first study to investigate individual differences in susceptibility to these biases. Expanding on two previous experiments, and utilizing as our sample 468 law students from twelve geographically diverse U.S. law schools, we examined whether differences in students' Need for Cognitive Closure (NFC) - a motivational desire for clear answers over ambiguity - would affect both their judicial outcome predictions and their "fair settlement value" assessments of a simulated personal injury case when assigned randomly to the role of plaintiff's or defendant's counsel. We also investigated whether high- or lowNFC scores would have any effect on the efficacy of a "consider-the-opposite" ("list the weaknesses of your case") prompt given to half of our subjects in an effort to de-bias these assessments. We found that a high need for closure intensifies self-serving bias in both students' judicial predictions and fair value assessments, and that bias in students' judicial predictions could be mitigated through de-biasing interventions, even with students high in need for closure. Bias in fairness assessments persisted, despite de-biasing prompts.
\end{abstract}

\section{INTRODUCTION}

Beginning students often enter law school expecting that the rules they study will provide clear and ready answers to legal problems. "What is the governing rule?" they want to know. "What is the answer to this hypothetical?" But the world of the practicing lawyer is, as often as not, clouded by ambiguity: The law may be vague or in flux. Conflicting legal rules may bear upon a single problem. The evidence needed to resolve the problem may be unavailable, incomplete or contradictory. Predicting the vagaries of human behavior is often dicey. Thus, advising clients about complex future events-how a judge or jury might resolve a disputed claim, how a business competitor might respond to a buyout offer or threatened lawsuit,

\footnotetext{
* James H. Stark is Roger Sherman Professor of Law Emeritus and Oliver Ellsworth Research Professor of Law, University of Connecticut School of Law. Maxim Milyavsky is Senior Lecturer in the Faculty of Business Administration, Ono Academic College, Kiryat Ono, Israel. We thank Jon Bauer, Miguel de Figueiredo, Douglas Frenkel, Deborah Hensler, Matthew Horowitz, Randall Kiser, Jennifer Robbennolt, Arne Roets, Peter Siegelman, Richard Wilson and the participants at the University of Connecticut Faculty Workshop for useful comments and insights on earlier drafts of this paper. We also thank Brittany Kaplan for helpful adminstrative support. This research was supported by a grant from the University of Connecticut Research Foundation.
} 
whether a government official will react favorably to one or another set of arguments offered on the client's behalf--often involves considerable uncertainty.

As law professors, we attempt to stimulate in our students flexible thinking and an appreciation for legal and factual indeterminacy. A former law dean ${ }^{1}$ had a stock orientation speech in which he exhorted students on their first day of law school to "revel in the ambiguity." The leading law school exam study guide, entitled "Getting to Maybe," is to similar effect. ${ }^{2}$ We spend three years with our students deconstructing legal texts, considering whether appellate decisions were adequately reasoned and rightly decided, and trying to promote multi-sided class-room discussions of complex (and sometimes "hot button") issues. In the spirit of liberal arts educators everywhere, we hope that with the proper training, we can inculcate dispassionate, open-minded judgment on the part of all our students. But is this realistic?

Previous empirical research has demonstrated the overall tendency of lawyers to adopt a too favorable view of the merits of their cases-a phenomenon that we term partisan role bias. ${ }^{3}$ The present study explores whether such general findings mask important differences among individuals in their tendency towards such self-serving bias. Our principal hypothesis is that law students, like individuals generally, vary substantially in their open-mindedness and tolerance for ambiguity; and that these differences are likely to predict their susceptibility to partisan bias when they make legal predictions and engage in fairness assessments in a representative lawyering role.

The question presented, which has not previously been investigated, is one with potentially significant policy implications. To the extent that partisan role biases affect lawyers, leading them to engage in "we-they" thinking or provide overly optimistic predictions to their clients about trial outcomes and other future events, this can prolong conflicts and impose substantial costs on both clients and society. As the authors of one study put it, it would be a matter of "high public interest" if bias reduction could be achieved in the general realm of legal decision making. ${ }^{4}$ Understanding the sources of self-serving bias and its variations among lawyers could provide useful information in pursuit of the goal of bias reduction.

This article is divided into four Parts. In Part One, we describe the empirical studies that formed the basis for our experiment. Part Two sets out the methodology and design of our study, as well as our research hypotheses. In Parts Three and Four, we describe our results

\footnotetext{
${ }^{1}$ The late George Schatzki, Dean of the University of Connecticut School of Law from 1994 to 2000.

2 Richard Michael Fischl \& Jeremy R. Paul, GetTing to Maybe: How to Excel on LaW SChool Exams (1999). The authors write: "What you will find inside the typical law school exam question is ambiguity, and we think that learning to live with it-indeed, learning to search it out and exploit it-is the key to doing well on law school exams." Id., at 17.

3 Throughout this article, we use the terms "partisan role bias" and "partisan bias" as umbrella terms encompassing a variety of judgmental biases that affect individuals when they are placed in a partisan lawyering stance. We are particularly interested in egocentric overconfidence and self-serving assessments of fairness. As applied to other non-legal and legal actors, this bias has sometimes been called "myside bias", see e.g., Jonathan BARON, THINKING AND DECiding (4th ed. 2008), "allegiance bias", see, e.g., Keith D. Markman \& Edward R. Hirt, Social Prediction and the "Allegiance Bias", 20 Soc. Cognition 58 (2002), or "adversarial allegiance bias". See, e.g., Bradley D. McAulliff \& Jeana L. Arter, Adversarial Allegiance: The Devil Is in the Evidence Details, Not Just on the Witness Stand, 40 LAW \& Hum. BEHAV. 524 (2016).

${ }^{4}$ Christopher Engel \& Andreas Glöckner, Role-Induced Bias in Court: An Experimental Analysis, 26 J. BeHAV. DECISION MAKING 272, 273 (2012).
} 
and discuss their possible limitations and implications. We close with some brief thoughts about possible areas for future research.

\section{PREVIOUS RESEARCH}

Three lines of empirical research bear upon the current investigation: 1) studies of the effects of various judgmental biases on disputants and lawyers; 2) attempts to reduce some of these biases through "consider-the-opposite" de-biasing interventions; and 3) general explorations of motivational differences that may affect individuals' susceptibility to judgmental bias in the first place.

\section{A. Judgmental Biases in Disputing}

Dispute resolution scholars have long recognized that, when placed in an adversary stance, disputants and their lawyers are susceptible to judgmental biases. These cognitive and motivational distortions include (but are not limited to) primacy effects; confirmation bias; the fundamental attribution error; and egocentric and self-serving biases, including inappropriate levels of confidence in one's judgment and decision-making abilities, contributions to past outcomes, and ability to predict or positively control future ones. ${ }^{5}$

A number of real-world studies demonstrate, for example, that litigators are more confident than accurate in their predictions of future trial verdicts. ${ }^{6}$ A 2008 empirical study of settlement decision making in 2000 California civil trials found that litigants and their attorneys commonly made serious settlement errors, rejecting negotiation offers better (often substantially so) than the results they achieved at trial. ${ }^{7}$ Neither the number of years of a lawyer's experience nor the ranking of his or her law school affected these error rates. Aggregated, these decisional errors were estimated to cost the clients in these matters more than $\$ 1$ billion, not including additional trial costs and attorneys' fees. ${ }^{8}$

The effects of overconfidence bias on disputing behavior have also been demonstrated in a number of simulation studies, suggesting that even random assignment to a simulated partisan role can lead to significant distortions in the way that subjects assess evidence,

\footnotetext{
5 For general reviews, see Robert S. Adler, Flawed Thinking: Addressing Decision Biases in Negotiation, 20 OHIO STATE J. DisP. Resol. 685 (2005); Richard Birke \& Craig R. Fox, Psychological Principles in Negotiating Civil Settlements, 4 Harv. Negot. L. ReV. 1 (1999); Russell Korobkin \& Chris Guthrie, Psychological Barriers to Litigation Settlement: An Experimental Approach, 93 MicH. L. REV. 107, 110 (1994); Douglas N. Frenkel \& James H. Stark, Improving Lawyers' Judgment: Is Mediation Training De-Biasing, 21 HARV. NEGOT. L. REV. 1, 7-8 (2015).. 6 See. e.g., Elizabeth F. Loftus \& Willem A. Wagenaar, Lawyers' Predictions of Success, 28 JuRIMETRICS J. 437 (1988); Jane Goodman-Delahunty et al., Insightful or Wishful: Lawyers' Ability to Predict Case Outcomes, 16 PSYCH., PUB. PoL'Y \& L. 133, 133-57 (2010).

7 Randall Kiser et al., Let's Not Make a Deal: An Empirical Study of Decision Making in Unsuccessful Settlement Negotiations, 55 J. EMPIRICAL LEGAL STUD. 551, 590 (2008) (finding that plaintiffs and defendants made settlement errors at a rate of $61 \%$ and $24 \%$ respectively, but that defense errors tended to be "whoppers," with a mean error size of $\$ 1,140,000$ compared to a mean error size for plaintiffs of $\$ 43,100$ ); RANDALL KISER, BEYOND

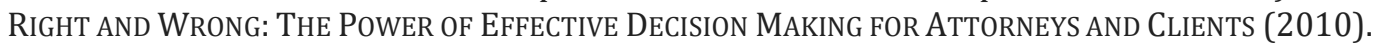

8 KiSER, BEYOND RIGHT AND WRONG, supra note 7, at 42-43.
} 
make predictions, and behave. Such partisan role bias has been shown to affect both parties ${ }^{9}$ and their agent-representatives. ${ }^{10}$

One illustrative experiment involving parties (which we build on here and is discussed in greater detail below), found that undergraduate and law student subjects, given identical case file materials from a factually ambiguous personal injury case, had widely different predictions of the most likely judicial outcome, depending on whether they were assigned to the plaintiff or defendant role. ${ }^{11}$ The researchers also found strong evidence of biased assimilation of the information provided, both in students' recall and weighting of arguments: each side recalled more arguments favoring their side's position than those favoring the other side, and each believed that a judge or jury would find "their" arguments superior to opposing ones. ${ }^{12}$ In a more recent study involving party representatives, Eigen and Listokin found that first year law students, randomly assigned to argue one side or another of closely-balanced appellate legal problem on behalf of a client in a moot court competition, each believed on average that the merits favored their side. ${ }^{13}$

In addition to distorting predictive accuracy in valuing cases, partisan role bias has also been shown to affect fairness assessments in bargaining. In general, when people are placed in competitive roles or settings involving conflict, their views of fairness are tinged with selfinterest. $^{14}$ The fundamental attribution error can lead disputants to attribute hostile meanings to other people's motives in conflict settings, increasing "hawkish" behaviors and making the resolution of disputes more difficult. ${ }^{15}$ When bargaining, negotiators often "reactively devalue" settlement offers made by the opposing side, simply on account of their source. 16

These kinds of biases often affect us unconsciously. Empirical research suggests that most human beings suffer from a bias "blind spot," causing them to think that "other people" are biased, while they are fair and objective. ${ }^{17}$ In part for this reason, neither instructing

\footnotetext{
${ }^{9}$ Leigh Thompson \& George Loewenstein, Egocentric Interpretations of Fairness and Interpersonal Conflict, 51 ORG. BEHAV. \& Hum. DeCISION PRoCESSES 176, 192 (1992).

${ }^{10}$ Engel \& Glöckner, supra note 4, at 1; Zev J. Eigen \& Yair Listokin, Do Lawyers Really Believe Their Own Hype, and Should They? A Natural Experiment, 41 J. LEGAL STUD. 239, 264 (2012).

${ }_{11}$ George Loewenstein et al., Self-Serving Assessments of Fairness and Pretrial Bargaining, 22 J. LEGAL STUD., 135, 150 (1993). This study is discussed in more detail, infra Part I.D.

12 Id., at $154-55$.

13 Eigen \& Listokin, supra note 10, at 263-64 and passim.

${ }_{14}$ See, e.g., Leigh L. Thompson \& Brian J. Lucas, Judgmental Biases in Conflict Resolution and How to Overcome Them, in The HANDBOoK OF Conflict Resolution 213,255 (2000); Paul W. Paese \& Robert D. Yonker, Toward a Better Understanding of Egocentric Fairness Judgments in Negotiation, 12 INT’L J. ConfliCT MGMT. 114, 128 (2001).

15 See, e.g., Volkan Topalli \& Edgar C. O'Neal, Retaliatory Motivation Enhances Attributions of Hostility When People Process Ambiguous Social Stimuli, 29 AgGressive BeHAV. 155, 167 (2003); Daniel Kahneman \& Jonathan Renshon, Hawkish Biases, in American Foreign Policy and the Politics of Fear: Threat Inflation Since 9/11 79 (A. Trevor Thrall \& Jane Cramer eds., 2009).

${ }^{16}$ Lee Ross, Reactive Devaluation in Negotiation and Conflict Resolution, in BARRIERS TO CONFLICT ReSOLUTION 26 (Kenneth Arrow et al., eds., 1995).

17 See, e.g., Emily Pronin, Perception and Misperception of Bias in Human Judgment, 11 Trends IN Cognitive SCI., 37, 41 (2007); Emily Pronin et al., Objectivity in the Eye of the Beholder: Divergent Perceptions of Bias in Self Versus Others, 111 Psychol. Rev. 781, 797 (2004); Emily Pronin et al., The Bias Blind Spot: Perceptions of Bias in Self Versus Others, Personality \& Soc. Psychol. Bull. 369 (2002) [hereinafter, Pronin et al., Personality \& Soc. PSYCHOL. BULL.].
} 
people about the distorting effects of biases on human decision making, nor admonishing them to be "fair and objective" has been found to be effective in reducing judgmental distortions. ${ }^{18}$ Monetary incentives, even substantial ones, have also been shown to have little effect in improving accuracy in predicting future court outcomes. ${ }^{19}$

\section{B. De-biasing by "Considering the Opposite"}

By contrast, one de-biasing technique that has shown considerable experimental success involves "consider the opposite" (CTO) prompts-interventions that ask subjects to generate, list, explain or imagine in detail reasons why their answer, hypothesis, prediction of future events or proposed decisions might be wrong. CTO prompts are a form of "counterattitudinal advocacy"20--role-playing exercises in which subjects are invited to generate and articulate opinions that may not correspond with their inner convictions. ${ }^{21}$

Consider-the-opposite prompts have been shown to reduce cognitive biases and improve decision making in a variety of domains not involving strong motivational investment. For example, they have been found to reduce subjects' overconfidence in the accuracy of their answers to general knowledge questions; ${ }^{22}$ to reduce belief persistence in the face of disconfirming evidence; ${ }^{23}$ and to improve evaluation of complex data in decision-making. ${ }^{24}$ Human beings are susceptible to cognitive biases because even when they know that the best decisions will be produced by considering all sides of a question, they tend to engage in onesided thinking. ${ }^{25}$ They rely on heuristics to arrive at their decisions and often truncate the search for additional information. ${ }^{26}$ CTO prompts appear to improve open-mindedness by

\footnotetext{
${ }^{18}$ Hal R. Arkes, Impediments to Accurate Clinical Judgment and Possible Ways to Minimize Their Impact, 49 J. CONSUlting \& CLINICAL PSYCHOL. 323, 327 (1981) (characterizing the technique of instructing subjects about a particular bias and then telling them not to influenced by it as "absolutely worthless," citing sources); Charles G. Lord et al., Considering the Opposite: A Corrective Strategy for Social Judgment, 47 J. PERSONALITY \& Soc. PSYchol. 1231, 1233-1234 (instruction to "weigh all the evidence in a fair and impartial manner" ineffective in reducing bias); Pronin et al., PERSONALITY \& Soc. PsyChOl. Bull., supra note 17, at 378 and passim (learning about biases ineffective in reducing their effects).

19 Engel \& Glöckner, supra note 4, at 278. (Student research participants offered 100 euros for accurate predictions of court ruling in simulated criminal case in which they assumed the role of defense counsel or prosecutor; financial incentive failed to reduce partisan role bias in their predictions.)

20 See, e.g., Richard L. Miller \& William Wozniak, Counter-Attitudinal Advocacy: Effort vs. Self-Generation of Arguments, 6 CuRRENT RESEARCH In SOCIAL PSYCHOL. 46 (2001).

21 For early work in this field, see Irving L. Janis \& Bert T. King, The Influence of Role Playing on Opinion Change, 49 J. ABnormal \& Soc. Psych. 211 (1954); Bert T. King \& Irving L. Janis, Comparison of the Effectiveness of Improvised Versus Non-improvised Role-playing in Producing Opinion Changes, 9 HuM. REL. 177 (1956).

22 Asher Koriat et al., Reasons for Confidence, 6 J. EXPERIMENTAL Psychol.: Hum. LEARning \& Memory 107 (1980).

23 Craig A. Anderson, Inoculation and Counter-Explanation: Debiasing Techniques in the Perseverance of Social Theories, 1 Soc. Cognition 126 (1982).

${ }^{24}$ Laura J. Kray \& Adam D. Galinsky, The Debiasing Effect of Counterfactual Mind-Sets: Increasing the Search for Disconfirmatory Information in Group Decisions, 91 ORG. BEHAV. \& HUM. DECISION PROCESSES 69 (2003).

25 BARON, supra note 3, at 55-58; Derek J. Koehler, Explanation, Imagination, and Confidence in Judgment, 110 Psychol. Bull. 499 (1991); Michael R. P. Dougherty et al., The Role of Mental Simulation in Judgments of Likelihood, 70 ORG. BeHAV. \& HuM. DECISION PROCESSES 135 (1997).

${ }^{26}$ See, e.g., Amos Tversky \& Daniel Kahneman, Judgment Under Uncertainty: Heuristics and Biases, in JuDGMENT UNDER UNCERTAINTY: HEURISTICS AND BIASES 3 (1982).
} 
reducing people's natural resistance to the consideration of alternatives once they have settled upon a focal hypothesis. ${ }^{27}$

Of course, cognitive biases often come in stronger, motivated forms as well. ${ }^{28}$ Motivational biases are judgmental distortions caused by a desire to believe something because of ego investment, ideological commitment, or a stake in the outcome. ${ }^{29}$ For example, when people with strong commitments to a political ideology are confronted with evidence that contradicts their beliefs, they tend to ignore or discount it--the "irrational belief persistence effect."30 Even here, consider-the-opposite prompts have shown some promise in reducing bias. ${ }^{31}$

In studies of case valuation and disputing, consider-the-opposite prompts have generated mixed results. In one negotiation simulation study, discussed further below, ${ }^{32}$ researchers found that a CTO "list the weaknesses in your case" instruction was highly effective at reducing overconfidence bias in case valuation. However, in a subsequent study of overconfidence bias on the part of practicing lawyers in actual cases, researchers were unable to replicate this result. Commenting on the discrepancy between their research findings and those reported in the earlier simulation study, the authors commented: "[a] more profound investment in the outcome of real-life cases may increase resistance to de-biasing interventions." 33

\section{The Need for Cognitive Closure}

The present study expands on previous research by examining whether individual differences-specifically differences regarding tolerance for ambiguity and openmindedness - affect law students' susceptibility to judgmental biases. Dispositional open versus closed-mindedness has been a subject of considerable social science research for more than thirty years and has been investigated in variety of ways. It has not, however, previously been a focus of much dispute resolution scholarship. ${ }^{34}$

In this study, we utilize a psychometric scale called the "Need for (Non-specific) Cognitive Closure Scale" (NFCS) to measure individual differences in this motivational trait. ${ }^{35}$ Need for

\footnotetext{
27 Koehler, supra note 25, at 502; Edward R. Hirt \& Keith D. Markman, Multiple Explanation: A Consider-anAlternative Strategy for Debiasing Judgments, 69 J. PERSONALITY \& SOC. PSYCHOL. 1069, 1083 (1995).

${ }^{28}$ See, e.g., Raymond S. Nickerson, Confirmation Bias: A Ubiquitous Phenomenon in Many Guises, 2 Rev. Gen. PSYCHOL. 175, 176 (1998).

${ }^{29}$ BARON, supra note 3, at 55, 199, 212.

30 Id.

31 See e.g., Lord et al., supra note 18, at 1231-37 (modifying previously-held views about capital punishment); Stephen J. Hoch, Counterfactual Reasoning and Accuracy in Predicting Future Personal Events, 11. J. EXPERIMENTAL PSYCHOL. 719 (1985) (mitigating overconfident predictions by MBA students regarding the timing and number of job offers they expected to receive upon graduation).

32 Linda Babcock et al., Creating Convergence: Debiasing Biased Litigants, 22 L. \& Soc. InquiRY 913, 919 (1998). For further discussion of this study, see infra Part I.D.

33 Goodman-Delahunty et al., supra note 6, at 151.

34 But see, Carsten K. W. de Dreu et al., On the Seizing and Freezing of Negotiator Inferences: Need for Cognitive Closure Moderates the Use of Heuristics in Negotiation, 25 Personality \& Soc. PsYchol. Bull. 348, 348 (1999).

35 Arie W. Kruglanski et al., Motivated Resistance and Openness to Persuasion in the Presence or Absence of Prior Information, 65 J. PersonaliTy \& Soc. PsYCHOL. 861, 876 (1993); Donna M. Webster et al., Motivated Language Use in Intergroup Contexts: Need-for-Closure Effects on the Linguistic Intergroup Bias, 72 J. PERSONALITY \& Soc. PSYCHOL. 1122, 1125 (1997).
} 
Cognitive Closure (NFC) refers to the extent to which individuals tend to prefer an answerany answer-to ambiguity or confusion. It is a generalized need, to be distinguished from the need for specific closure, i.e., the desire for particular answers to questions for specific (e.g., ego-protecting) reasons. Although environmental factors have been shown to affect individuals' desire for closure in particular situations, ${ }^{36} \mathrm{NFC}$ is also believed to be a stable individual motivational disposition, unrelated to a person's general intelligence. ${ }^{37}$

The NFCS is a 5-factor scale that tests for different motivational factors that may each contribute to an individual's general need for closure: preference for order and structure, discomfort with ambiguity, decisiveness in decision-making, desire for stable knowledge and predictability, and closed-mindedness. ${ }^{38}$ This scale has been translated into multiple languages and different versions of it have been used in more than one hundred social science experiments, both in the U.S. and elsewhere. Most NFC research to date has focused on lay, not expert decision making. ${ }^{39}$

According to the scale's principal developer, the need for cognitive closure is "involved in all human judgments and decisions and hence its effects must be considered value free in principle." 40 For example, low-NFC individuals may be more motivated to entertain nuance and complexity than high-NFC individuals, but they may also be less comfortable and consistent in making decisions, and less committed to their clients. Conversely, high-NFC individuals may be more decisive and committed than low-NFC individuals, but less creative in group processes, less able to tailor a message to an audience, and more likely to view conflict in competitive rather than cooperative terms. ${ }^{41}$

There is good reason to hypothesize that need for closure variations may have an influence on law students' and lawyers' predictive judgments and fairness assessments when they are engaged in a representative lawyering role. Among other effects, high- (versus low-) NFC individuals have been shown to have a strong tendency to reduce their discomfort with uncertainty by forming judgments quickly and impulsively, based on early-received information (primacy effects, or "seizing"); to be resistant to subsequent relevant information and persuasion in order to maintain their beliefs (irrational belief persistence, or "freezing"); to have undue subjective confidence in the validity of their own views (the "true believer" effect); and to be less able to generate alternative hypotheses to explain

\footnotetext{
${ }^{36}$ For example, time pressure, noise and mental fatigue have been shown to increase the need for cognitive closure, while accountability to others decreases it. See, e.g., Antonio Chirumbolo, et al, Effects of Need for Closure on Creativity in Small Group Interactions, 18 EUR. J. PERS. 265, 265 (2004) (summarizing studies).

37 Donna M. Webster \& Arie W. Kruglanski, Individual Differences in Need for Cognitive Closure, 67 J. PERSONALITY \& Soc. PSYCHOL. 1049, 1055-56 (1994).

38 Kruglanski et al., supra note 35, at 876; Arie W. Kruglanski et al., Psychological Theory Testing Versus Psychometric Nay-Saying: Comment on Neuberg et al.'s (1997) Critique of the Need for Closure Scale, 73 J. PERSONALITY \& SOC. PSYCHOL. 1005, 1009 (1997).

${ }^{39}$ Arne Roets et al., Effects of Dispositional Need for Closure and Training on Medical Decision Making, 34 MED. DECISION MAKING 144, 144 (2014).

40 Arie W. Kruglanski, The Psychology of Closed Mindedness 135 (2004).

41 Id. at 96-97, 100-105, 122-123 and passim; Agnieszka Golec \& Christopher M. Federico, Understanding Responses to Political Conflict: Interactive Effects of the Need for Closure and Salient Conflict Schemas, 87 J. PERSONALity \& Soc. PSYCHOL. 750 (2004)
} 
ambiguous events. ${ }^{42}$ NFC variations may also affect the ability of individuals to engage in perspective-taking and avoid stereotyping others. ${ }^{43}$

Lawyers are called upon to make difficult predictions, based on their evaluation of complex and often conflicting evidence, received over time. It seems reasonable to hypothesize that high-NFC attorneys may be more susceptible than low-NFC attorneys to the influence of their clients' narratives-the first version of events they are likely to hear, as well as more resistant to revising their assessments of a legal matter in light of new information learned through witness interviews, review of documents, depositions and the like. The fact that lawyers often work in high conflict settings, in which parties often engage in negative attributions about their opponents, may exacerbate these tendencies.

\section{Summary of Precursor Studies}

In order to test the effects of dispositional need for closure on lawyering judgment, we modified two experiments, conducted in 1993 and 1998 (the 1993 Experiment and the 1998 Experiment, respectively). ${ }^{44}$ In the 1993 Experiment, a group of eighty undergraduate and eighty law students were given condensed but identical case file materials from an actual, recently litigated motorcycle accident case, which students were told had been arbitrated by a retired Texas judge. Plaintiff Jones was a motorcycle driver who suffered injury when he was rear-ended by Johnson, the defendant motorist. Jones seeks $\$ 100,000$ in damages for his injuries. The accident occurred in a split second, at an intersection with poor sight lines that witnesses say is hazardous. No witnesses saw the actual collision. The defendant admits that he had been drinking earlier in the day, but there is conflicting evidence about whether he was impaired at the time of the collision. The plaintiff may or may not have been contributorily negligent in entering the intersection; under Texas law, he will recover nothing if his negligence is determined to have exceeded the defendant's. The physical evidence is inconclusive as to how the accident occurred. The plaintiff's "pain and suffering" damages claim appears overstated in relation to the medical evidence in support of it. Neither litigant is especially articulate or persuasive. 45 In short, "Jones v. Johnson" is an ordinary car accident case of a kind litigated in state courts every day. It is legally simple, but factually ambiguous. If tried to a judge or jury, widely variable outcomes are possible.

Student subjects in the 1993 Experiment were randomly assigned to the role of plaintiff or defendant and asked to predict what monetary award the judge-arbitrator would order and what settlement outcome would be "fair." They were then paired off and instructed to negotiate in an effort to reach a settlement. 46

Note that, although subjects were told that a judge had arbitrated the case and were asked to predict his "award," this was merely an artifact of the experiment. (In actuality, an expert with relevant civil litigation experience read the materials and placed a "value" on the case.) The researchers were not concerned with how close or far students' predictions were from the (faux) judicial arbitration award or whether their predictions were "correct." Rather,

\footnotetext{
42 Webster \& Kruglanski, supra note 37, at 1057-58 (Study 4).

43 Shan Sun et al., Does Perspective Taking Increase or Decrease Stereotyping? The Role of Need for Cognitive Closure, 94 PERSONALITY \& INDIVIDUAL DIFFERENCES 21 (2016).

44 Loewenstein et al., supra note 11; Babcock et al., supra note 32.

45 Loewenstein et al., supra note 11, at 145-47; "Jones v. Johnson" case materials on file with senior author.

46 Loewenstein et al., supra note 11, at 145-47.
} 
they were interested in whether, and to what extent, plaintiffs' and defendants' arbitral predictions and fair settlement value assessments would differ from each other, simply on account of their assigned role. They chose a rich and factually ambiguous case file, with a variety of possible arguments available to each side, because they hypothesized that selfserving assessments were more likely to occur in such situations than with a simpler, more stylized fact pattern. ${ }^{47}$

The researchers found, on average, that students assigned to the role of plaintiff predicted an award by the judge that was $\$ 14,527$ higher than that predicted by students assigned to the defendant role, and that their fair settlement estimates were $\$ 17,709$ higher than defendants' - biases of a substantial magnitude, given that the judge's "award" was only $\$ 30,560$. The researchers also found (unsurprisingly) that the larger the difference in both predicted judicial awards and fair value assessments within each negotiating pair, the longer their negotiations took and the greater the likelihood they would experience bargaining impasse. 48

In the follow-up 1998 Experiment, the researchers replicated their 1993 Experiment. However they also tested the efficacy of a simple "consider-the-opposite" (CTO) instruction in de-biasing judgment and improving bargaining behavior on the part of 98 MBA students at two different schools. The researchers found that a "list the weaknesses in your case" CTO prompt (given to half of the plaintiffs and half of the defendants, but not to students in the control condition) was highly effective in reducing bias and promoting settlement. ${ }^{49}$

\section{E. Alterations to Precursor Studies}

In the current study, we revised and expanded on these two experiments, utilizing only law students as our subjects and introducing NFC testing as a third variable. We were attracted by the factual ambiguity and realism of the original Texas case file materials, and so decided to use them again. However, for reasons described below, we made four significant alterations to the design of the original experiments that complicate the comparison of our results with those from the earlier ones.

First, we assigned students to the role of plaintiff's or defendant's counsel rather than to the role of litigants themselves, in order to determine if, as agents, they would demonstrate a similar or different degree of partisan role bias as participants assigned to the role of plaintiffs and defendants in the two previous studies. (In order to help them assume this role, we also gave them some brief instructions on Texas tort and evidence law so that they would understand the legal rules that would apply to the case.)

Second, because we were utilizing other professors' students and not our own and wanted them to take the exercise seriously, we increased the reward structure for accurate predictions of the judge's arbitration award, from (a largely symbolic) \$1 for all valuations

47 Id. at 150.

48 Id.

49 Babcock et al., supra note 32, at 918-20. In the control condition, students assigned to the plaintiff role submitted arbitral predictions that were, on average, more than $\$ 20,000$ higher than those students assigned to the defendant role. In the de-biasing condition, the average differential in arbitral predictions was reduced to less than $\$ 5000$. Thirty-five percent of student pairs in the control condition failed to settle their case within the 30-minute negotiation period, but only $4 \%$ failed to settle in the de-biasing condition. Id. For a comparative discussion of the impact of CTO on law students in our study, see infra Part IV.A. 
within $\$ 5000$ of the judge's award to a possible high of $\$ 100$ for predicted valuations closest to that award.

Third, we modified the de-biasing prompt given to half of the students in the sample. In the 1998 Experiment, students in the de-biasing groups were instructed as follows:

In experiments based on this case we have found evidence of "self-serving interpretations of fairness." When we ask plaintiffs and defendants to predict the ruling of the judge, and to tell us what they think is a fair settlement of the case, plaintiffs' answers to both questions are typically $\$ 20,000$ greater than defendants'. Furthermore, when the difference between the plaintiff and the defendant is large-when the plaintiff thinks a much higher settlement is fair than does the defendant-the parties are much less likely to settle the case and more likely to "go to court" and incur legal expenses. This occurs because each side is "holding out" for what they legitimately think is a fair settlement. Disputants don't always think carefully about the weaknesses in their own case and are therefore surprised when the judge's ruling is worse than their expectations. For plaintiffs, this means that the judge's award is worse than their expectations. For defendants, this means that the judge's award is often greater than their expectations. Therefore, please think carefully about the weaknesses in your case. In the space below, please list the weaknesses in your own case. ${ }^{50}$

We redacted the italicized sentence from our de-biasing prompts, concerned that it might be too suggestive, and retained the remaining language.

Fourth, and importantly, student participants in both the 1993 and 1998 Experiments were asked the following two questions:

1. What is your best guess of the amount of the judge's award?

2. What do you consider a fair amount for [the plaintiff] to receive in an out of court settlement from the vantage point of a neutral third party?

This wording of question 2 seemed to us to combine, and perhaps conflate, two different ways of assessing a case for settlement. As previously described, prior research demonstrates that people often make fairness assessments based on self-serving, subjective standards, and not "from the vantage point of a neutral third party." To better distinguish more objective and more subjective ways of assessing a case, we changed the formulation of question 2 to read: "Irrespective of the judge's award, what would you consider a fair amount for [the plaintiff] to receive in damages to settle this case out of court?" By framing the question in this way, we were attempting to prompt participants to differentiate between the outcome they would consider most likely and the outcome they would deem most just. ${ }^{51}$

\footnotetext{
50 Materials on file with senior author (emphasis added).

51 We made other minor changes to the original experiments as well. First, we changed the name of the case file from "Jones v. Johnson" to "Platt v. Dixon" to more clearly distinguish the two litigants and make it easier for participants to remember their assigned role. Second, to account for inflation, we updated all financial figures in the case by a factor of $50 \%$, including plaintiff's demand for damages (changed from $\$ 100,000$ to $\$ 150,000$ ). Third, we administered this survey as an online, unmonitored, out-of-class exercise (with a recommended completion time of 45 minutes), rather than as in-class, written one.
} 


\section{Methodology of StUdy}

\section{A. Hypotheses}

Our study was designed to test four hypotheses: First, we expected to replicate previous findings of partisan role bias on the part of lawyers and law students in a representative role, i.e., we expected that participants representing the plaintiff would assign higher valuations to the case than those representing the defendant, despite assuming the role of agents rather than principals as in the previous two studies.

Second, we expected that the effects of partisan role bias would be greater for participants with high (vs. low) dispositional need for closure.

Third, we expected to replicate the de-biasing effect of consider-the-opposite prompts, by demonstrating reduced partisan bias in the de-biasing (vs. control) condition.

Fourth, given their preference for certainty over ambiguity, we hypothesized that individuals with a high need for closure would be more resistant to de-biasing interventions than individuals with a low need for closure.

\section{B. Sample}

After receiving IRB approval to conduct the study, we sent out list serve solicitations describing its purpose and design to U.S. law professors teaching dispute resolution and clinical courses. Fourteen instructors from twelve geographically diverse public and private law schools (Arizona State, Brooklyn, Case Western Reserve, University of Connecticut, Laverne, University of Missouri, New England, University of Oregon, Quinnipiac, University of South Carolina, University of Wisconsin and Vermont Law School) participated, after securing approvals from their home institutions. Instructors were requested to provide the materials to their students as an online survey homework assignment, to be followed by inclass negotiations based on students' randomly assigned role in the case. The in-class negotiations (which most but not all instructors assigned) were not part of our investigation.

Four hundred and ninety-two participants completed the study online. Despite our efforts to eliminate role confusion, twelve participants reported in the debriefing questions being in the wrong role (e.g., representing the plaintiff despite having received instructions to represent the defendant). In addition, seven participants did not list any weaknesses in their case, despite being given a de-biasing prompt instructing them to do so. Three participants did not complete the Need for Closure questionnaire. One participant completed the study twice and one participant received the wrong instructions because of a technical problem in the software that was later fixed. We excluded these twenty-four participants from the subsequent analyses.

Thus, the main analyses refer to 468 participants (251 females and 216 males, 1 participant did not report their gender; $M_{\text {age }}=25.6, S D_{\text {age }}=4.24$ ). Of these, 251 were firstyear students, 121 were second-year students and 92 were third-year students. Four subjects were graduate-level or foreign students and one subject did not indicate his or her year. Almost all participants (455 of 468) had completed at least the negligence portion of their required first-year Torts course before taking the survey. Only 142 participants had 
completed the study of Evidence. None of these demographic variables-gender, year in law school or completed coursework--had any statistically significant effect on any of the measures tested in this study.

\section{Procedure and Materials}

All student subjects completed the study utilizing the Qualtrics.com online platform. The computer program randomly assigned participants to one of four conditions depending on their role in the task (plaintiff's attorney/defendant's attorney) and whether or not they would receive the de-biasing prompt (de-biasing/control). All subjects were provided a general information sheet and consent form describing the study. They were told that they would read a condensed version of a case file from an actual personal injury case in which they would represent either the plaintiff or the defendant. They were further informed that they would be asked to predict the judge-arbitrator's award in the case, as well as to state what a fair settlement outcome in the case would be, irrespective of that award.

In order to incentivize participants to work carefully on the task, we instructed them that their class instructor would be asking them to negotiate with another student in a future class based on the case valuation estimates they provided online. As an additional incentive, we promised ten monetary prizes (gift cards worth $\$ 50$ or $\$ 100$ ) to participants across the entire pool of subjects whose estimations of the judge's award was closest to the "actual" award $(\$ 45,840)$. Participants were also told that they could choose to complete a different class assignment (e.g., reading a paper) instead of this assignment, but none selected this option. After consenting to participate in the study, participants answered a few demographic questions and completed the NFC 42-item inventory (See Appendix below).

Next, participants were presented with identical case file materials from Platt v. Dixon. The file consisted of 27 pages of information, including the litigation complaint and answer, a diagram of the accident site, excerpts from party and witness depositions, and documents pertaining to the parties' previous driving records as well as plaintiff's claimed medical expenses and other out-of-pocket damages. After reading these case materials, half of the participants were given the de-biasing prompt in which they were alerted to the existence of partisan bias in case valuation and asked to write down potential weaknesses in their client's case. All students were then asked for their case evaluations, in two parts:

After reading the case materials, but before you are assigned by your instructor to negotiate, please answer the following questions:

1) What is your best guess of the amount of the judge's award, if any, to Platt? Enter a number between 0 and $\$ 150,000$ below.

2) Irrespective of the judge's award, what would you consider a fair amount for Platt to receive in damages to settle this case out of court? Enter a number between 0 and $\$ 150,000$ below.

At the end of the survey, participants answered a few questions designed to assess whether they understood the instructions and followed them as intended. To confirm that the participants knew the role to which they were assigned, we asked them to indicate whether they represented the plaintiff or the defendant. We also asked participants whether 
there was anything in the instructions for the study with which they struggled. Finally, we asked participants if they could determine the purpose of the study. No one guessed the purpose of the NFC Scale.

\section{Design}

The design of this study was Case Valuation (Judge's award/Fair amount) x Assigned Role (Plaintiff attorney/Defendant attorney) x De-biasing Condition (Control/De-biasing). The first variable was manipulated within participants and the other two variables were manipulated between participants. In addition, we measured participants' need for cognitive closure and analyzed the data to determine whether high-NFC subjects were more susceptible to self-serving bias and more resistant to de-biasing prompts than low-NFC subjects.

\section{STUDY RESULTS}

\section{A. Reliability of NFC}

Before conducting the main analyses to test our predictions, we tested the reliability of the NFC scale. ${ }^{52}$ The obtained reliability was high (Cronbach's alpha $=0.85$ ), the mean score was 3.78 with 3.5 being the midpoint on the 6-point Likert scale. As can be seen from the histogram of the NFC scores below (Figure 1), the distribution of the NFC scores is normal and tight around the mean (SD $=0.42$ ). ANOVA with role (defendant attorney/plaintiff attorney) and de-biasing condition (control/de-biasing) as between participants' factors revealed no significant differences in NFC among the experimental conditions, $p>.21$.

\footnotetext{
52 Some NFC scholars have argued that the "decisiveness in decision-making" sub-scale on the original NFCS is an independent and distinctive dimension, not significantly related to the other four factors on the scale. See, e.g., Arne Roets \& Alain Van Hiel, Separating Ability from Need: Clarifying the Dimensional Structure of the Need for Closure Scale. 33 PeRsonality \& Soc. Psych. Bulletin 266 (2007). To test the robustness of our findings, we reanalyzed our data to determine if any would be affected by dropping the decisiveness sub-scale from our data analysis, as some other researchers have done. See, e.g., Stefano Livi, et al., Epistemic Motivation and Perpetuation of Group Culture: Effects of Need for Cognitive Closure on Trans-Generational Norm Transmission, 129 ORG. BEHAV. \& HUMAN DECISION PROCESSES 105 (2015). None of the findings presented below was affected by this re-analysis.
} 


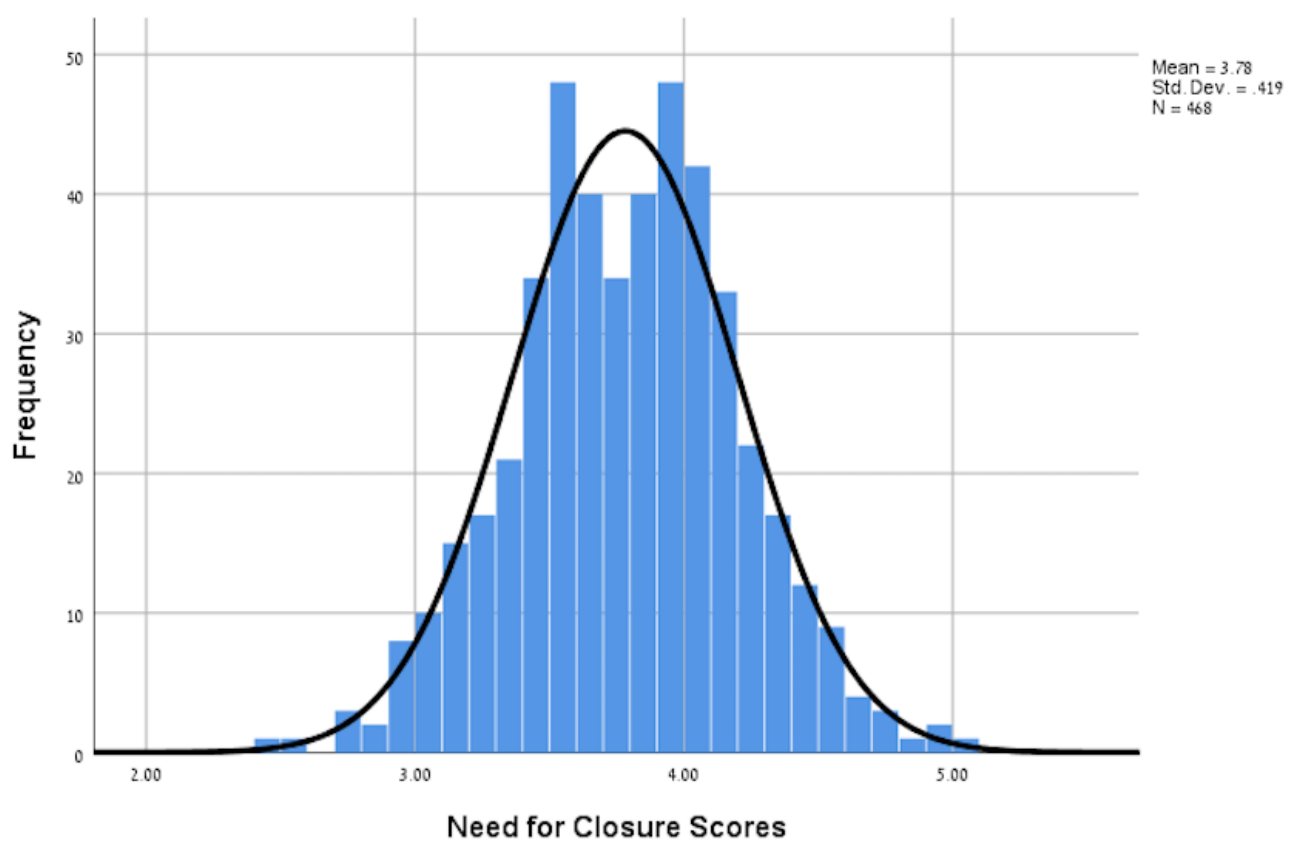

Figure 1. NFC scores histogram.

\section{B. Main Analyses}

We used a random intercept mixed linear model to analyze participants' valuations of the case. ${ }^{53}$ Because each participant provided two valuations of the case-what could be called an objective valuation-predicting what a neutral, impartial judge would award in arbitration, and a subjective evaluation-stating what settlement amount, in his or her opinion, would be "fair," we coded the Case Valuation variable as the Level 1 (within participant) predictor (-0.5 - the judge's award and 0.5 - fair amount), so that 0 would represent the average of the objective and subjective valuations. Similarly, we centered on zero the Level 2 (between participants) predictors - the assigned role ( -0.5 - defendant attorney, 0.5 - plaintiff attorney) and the de-biasing condition (-0.5 - control, 0.5 - debiasing). Finally, the NFC scores were linearly transformed so that their mean would also be centered at zero. The results of this analysis are presented in Table 1, below. We then report these analyses for each of our hypotheses.

\footnotetext{
53 This model is the appropriate model for analyzing data that include both nested data (in our design, an arbitral prediction and an assessment of fair value were nested within individuals) and continuous predictors (in our design, this was Need for Cognitive Closure. See Judith D. Singer, Using SAS PROC MIXED to Fit Multilevel Models, Hierarchical Models, and Individual Growth Models, 23 J. Educ. \& BEHAV. STAT. 323 (1998).
} 
Representative Lawyering Bias and Need for Closure

Table 1: Mixed-level Linear Model

\begin{tabular}{|c|c|c|c|c|c|c|}
\hline & $B$ & $S E$ & $t$ & $d f$ & $p$ & $95 \% C I$ \\
\hline Intercept & 46699 & 1392 & 35.54 & 460 & 0.000 & $44.0 \mathrm{~K}, 49.4 \mathrm{~K}$ \\
\hline Case Valuation & -1849 & 1147 & -1.61 & 460 & 0.108 & $-4.1 \mathrm{~K}, 0.4 \mathrm{~K}$ \\
\hline Role & 9185 & 2785 & 3.30 & 460 & 0.001 & $3.7 \mathrm{~K}, 14.7 \mathrm{~K}$ \\
\hline De-biasing condition & -1333 & 2784 & -0.48 & 460 & 0.632 & $-6.8 \mathrm{~K}, 4.1 \mathrm{~K}$ \\
\hline NFC & 4698 & 3358 & 1.40 & 460 & 0.163 & $-1.9 \mathrm{~K}, 11.3 \mathrm{~K}$ \\
\hline Case valuation $\mathrm{x}$ Role & 13456 & 2294 & 5.87 & 460 & 0.001 & $8.9 \mathrm{~K}, 18.0 \mathrm{~K}$ \\
\hline Case valuation $\mathrm{x}$ De-biasing & -4136 & 2293 & -1.80 & 460 & 0.072 & $-8.6 \mathrm{~K}, 0.3 \mathrm{~K}$ \\
\hline Case valuation $\mathrm{x}$ NFC & -5011 & 2766 & -1.81 & 460 & 0.071 & $-10.4 \mathrm{~K}, 0.4 \mathrm{~K}$ \\
\hline Role x De-biasing & -5199 & 5571 & -0.93 & 460 & 0.351 & $-16.1 \mathrm{~K}, 5.7 \mathrm{~K}$ \\
\hline Role x NFC & 14260 & 6737 & 2.12 & 460 & 0.035 & $1.0 \mathrm{~K}, 27.5 \mathrm{~K}$ \\
\hline De-biasing $x$ NFC & -2494 & 6722 & -0.37 & 460 & 0.711 & $-15.7 \mathrm{~K}, 10.7 \mathrm{~K}$ \\
\hline $\begin{array}{l}\text { Case valuation } x \text { Role } x \text { De- } \\
\text { biasing }\end{array}$ & 10668 & 4588 & 2.33 & 460 & 0.021 & $1.7 \mathrm{~K}, 19.7 \mathrm{~K}$ \\
\hline Case valuation $\mathrm{x}$ Role $\mathrm{x}$ NFC & 910 & 5549 & 0.16 & 460 & 0.870 & $-10 \mathrm{~K}, 11.8 \mathrm{~K}$ \\
\hline $\begin{array}{l}\text { Case valuation } x \text { De-biasing } x \\
\text { NFC }\end{array}$ & 4457 & 5537 & 0.81 & 460 & 0.421 & $-6.4 \mathrm{~K}, 15.3 \mathrm{~K}$ \\
\hline Role x De-biasing x NFC & -6559 & 13486 & -0.49 & 460 & 0.627 & $-33.1 \mathrm{~K}, 19.9 \mathrm{~K}$ \\
\hline $\begin{array}{l}\text { Case valuation } x \text { Role } x \text { De- } \\
\text { biasing } x \text { NFC }\end{array}$ & -2268 & 11108 & -0.20 & 460 & 0.838 & $-24.1,19.6 \mathrm{~K}$ \\
\hline
\end{tabular}

Note. Participants' predictions were regressed onto one Level 1 (within participant) predictor Case Valuation ( -0.5 - the judge's award and 0.5 - fair amount), and three Level 2 (between participants) predictors - Role (0.5 - defendant attorney, 0.5 - plaintiff attorney), the de-biasing condition ( -0.5 - control, 0.5 - de-biasing), and NFC scores (centered at zero). The letter "K" indicates thousands of dollars.

\section{Hypothesis 1: Effects of Assigned Role on Overall Case Assessments}

Our first hypothesis was that students randomly assigned to the role of plaintiff's or defendant's counsel would exhibit partisan role bias in their overall case assessments, just as students assigned to a party role had in the 1993 and 1998 Experiments. Our findings generally support this hypothesis, with some features and differences from the findings of the previous Experiments that are intriguing.

\section{Results for control and de-biasing groups combined}

The overall results for students assigned to both the control group and the de-biasing group on each side of the litigation are presented in Table 2, below: 
Representative Lawyering Bias and Need for Closure

Table 2: Case Evaluations by Students Across Entire Sample (Control plus De-biasing Conditions)

\begin{tabular}{llll}
\hline & Plaintiff Lawyer & Defendant Lawyer & Partisan Bias \\
\hline \multirow{2}{*}{ Overall \$ Value } & $51.3 \mathrm{~K}$ & $42 \mathrm{~K}$ & $9.3 \mathrm{~K}^{* *}$ \\
& $(31.9 \mathrm{~K})$ & $(28.1 \mathrm{~K})$ & $(30.0 \mathrm{~K})$ \\
Arbitral Prediction & $48.9 \mathrm{~K}$ & $46.5 \mathrm{~K}$ & $2.5 \mathrm{~K}$ \\
& $(33.2 \mathrm{~K})$ & $(34.0 \mathrm{~K})$ & $(33.6 \mathrm{~K})$ \\
Fair Value & $53.6 \mathrm{~K}$ & $37.5 \mathrm{~K}$ & $16.1 \mathrm{~K}^{* * *}$ \\
& $(35.2 \mathrm{~K})$ & $(27.2 \mathrm{~K})$ & $(31.4 \mathrm{~K})$ \\
\hline
\end{tabular}

Note. In all the tables that follow, numbers in parentheses indicate standard deviations. The letter "K" indicates thousands of dollars.

${ }^{* *} p<.01$

${ }^{* * *} p<.001$

“Overall \$ value” in Table 2 represents students' mean estimates of the value of Platt v. Dixon, averaging their predictions of the most likely arbitral award and their assessments of the case's "fair settlement" value. "Partisan Bias" refers to the mean difference in overall case valuations submitted by plaintiff and defendant lawyers. As can be seen from this table, the main effect of role was significant, $t(460)=3.30, p=.001$, Cohen's $d=0.31$, indicating that, on average, participants representing the plaintiff $(n=240$; including both those who received the de-biasing prompt and those who did not) predicted case values (averaged across the fair settlement amount and the judge's predicted award) to be \$9,309 higher than those who represented the defendant $(n=228)$. This result replicates previous findings of partisan role bias on the part of representative lawyers.

We acknowledge the artificiality of averaging our participants' arbitral predictions and fair settlement assessments to yield a combined "overall value" for Platt v. Dixon. We report the measure in this way because it is consistent with previous research, which has mostly treated partisan role bias on the part of lawyers or law students as a unitary phenomenon. For example, in concluding that most lawyers are more overconfident than accurate in their litigation forecasts, Goodman-Delahunty and her colleagues asked civil and criminal litigators to specify an outcome in a pending case that they would consider their "minimum goal" for the case, as well as the probability they "will achieve this outcome or something better." 54 The researchers did not ask their subjects whether their specified goal was based on an objective prediction of the most likely trial result, their sense of what a "fair" outcome would be, or some combination of these two factors. Their research design did not distinguish these different ways of valuing a case, as ours enabled us to do.

When in fact we disaggregated these two valuation methods among the entire sample of respondents, we found that participants' "fair value" assessments were far more susceptible to partisan role bias than were their predictions of the most likely arbitral award. Specifically, plaintiff lawyers' estimates of the fair settlement value of the case were $\$ 16,134$ higher than the estimates of those who represented the defendant, $t(612)=5.28, p<.001, d$

${ }^{54}$ Goodman-Delahunty et al., supra note 6, at 139. 
$=0.51$. By contrast, when it came to predicting the judge's most likely award, the difference between the plaintiff lawyer and defense lawyer predictions was only $\$ 2,483$, an effect that was not statistically significant, $t<1$. This greater susceptibility of participants' fair value assessments to partisan bias was significant, $b=13,456$, $s e=2,294, \beta=.10$, se $=.02, t(460)=$ 5.87, $p<.0001$.

\section{Results for control group only}

We then analyzed the results for the students in the control group only, so as to be able to compare those results to the findings of the 1993 Experiment, which did not include a debiasing condition as part of its design. These results are presented in Table 3 below.

Table 3: Case Evaluations by Students in the Control Condition Only

\begin{tabular}{llll}
\hline & Plaintiff Lawyer & Defendant Lawyer & Partisan Bias \\
\hline \multirow{2}{*}{ Overall \$ Value } & $53.5 \mathrm{~K}$ & $41.2 \mathrm{~K}$ & $12.3 \mathrm{~K}^{* *}$ \\
& $(34.6 \mathrm{~K})$ & $(29.5 \mathrm{~K})$ & $(32.1 \mathrm{~K})$ \\
Arbitral Prediction & $51.5 \mathrm{~K}$ & & \\
& $(35.2 \mathrm{~K})$ & $43.3 \mathrm{~K}$ & $8.2 \mathrm{~K}^{*}$ \\
Fair Value & $55.5 \mathrm{~K}$ & $(33.8 \mathrm{~K})$ & $(34.5 \mathrm{~K})$ \\
& $(37.6 \mathrm{~K})$ & $39.1 \mathrm{~K}$ & $16.4 \mathrm{~K}^{* *}$ \\
\hline
\end{tabular}

${ }^{*} p<.1$

${ }^{* *} p<.01$

${ }^{* * *} p<.001$

As can be seen from Table 3, random assignment to the role of attorney for plaintiff or defendant in the control condition produced a difference in overall case evaluations of $\$ 12,261$, which was also statistically significant, $t(460)=2.98, p=.003, d=0.38$.

Again, however, when we disaggregated the differences in students' predictions of the most likely judicial arbitral award and their assessments of the case's fair settlement value, different patterns emerged. The differential between plaintiff lawyers' and defense lawyers' assessments of a fair settlement value for the case was more than double the differential in their arbitral predictions. In the control condition, the plaintiff's lawyers predicted arbitral awards that were $\$ 8,172$ higher than those of the defense lawyers, $t(612)=1.81, p=.07, d=$ 0.24 , a marginally significant difference. By contrast, the plaintiff's lawyers' fair settlement value assessments were $\$ 16,351$ higher than those of the defense lawyers-a difference that was highly significant, $t(612)=3.70, p<.0001, d=0.49$. As in the across de-biasing conditions analysis reported above, this greater susceptibility of participants' fair value assessments to partisan bias was significant, $b=8,077$, se $=3,262, \beta=0.06$, se $=0.02, t(460)$ $=2.48, p=.014$.

We also wanted to compare the magnitude of the partisan bias exhibited by students in our control condition to that found in those earlier experiments. The effect size of partisan 
role bias on students' arbitral predictions in our study was much smaller than those obtained by both the 1993 Experiment and the 1998 Experiment. (Cohen's $d=0.24$ vs. $d=0.42$ and $d$ $=0.76$ ). By contrast, the magnitude of partisan bias in subjective fairness assessments in our study was similar to that reported by the 1993 Experiment ( $d=0.49$ vs. $d=0.53) .{ }^{55}$

\section{Hypothesis 2: Effects of NFC on Partisan Role Bias}

Our second hypothesis - and the main focus of our study - was that our data would show an interaction between participants' Need for Cognitive Closure scores and their susceptibility to partisan role bias. Consistent with that hypothesis, we found that participants with higher NFC scores were far more susceptible to partisan role bias than those with lower NFC scores, $b=14,260$, $s e=6,737, \beta=.09$, $s e=.04, t(460)=2.12, p=.035$. This interaction is depicted in Figures 2 through 4 below.

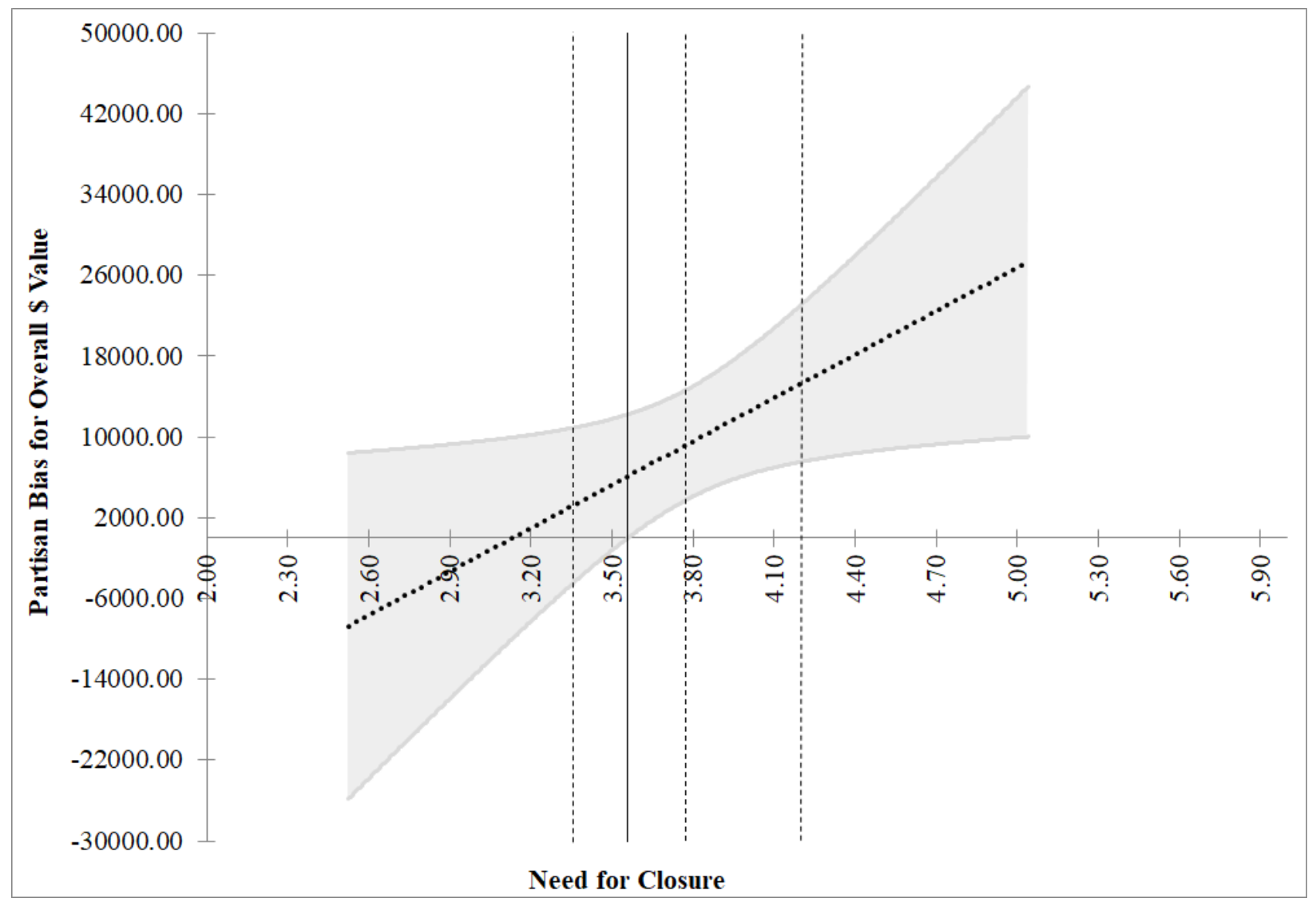

Figure 2. Partisan bias for overall \$ value predicted from individuals' NFC scores. The solid line indicates the critical value of NFC above which the partisan bias becomes significant. The middle, left and right dashed lines

\footnotetext{
${ }^{55}$ We reached this conclusion by comparing our effect sizes to the calculated effect sizes for arbitral predictions and subjective fairness respectively, based on the mean differences, standard errors and sample sizes provided in Loewenstein, et al., supra note 11, at 151 (Table 2, rows 1 and 2) and Babcock, et al., supra note 32, at 31, (Table 2, row 3). For potential reasons for this discrepancy, see infra Part IV.B.
} 
Representative Lawyering Bias and Need for Closure

indicate the mean values of NFC and 1SD below and above the mean, respectively. The gray bands represent the $95 \%$ confidence intervals.

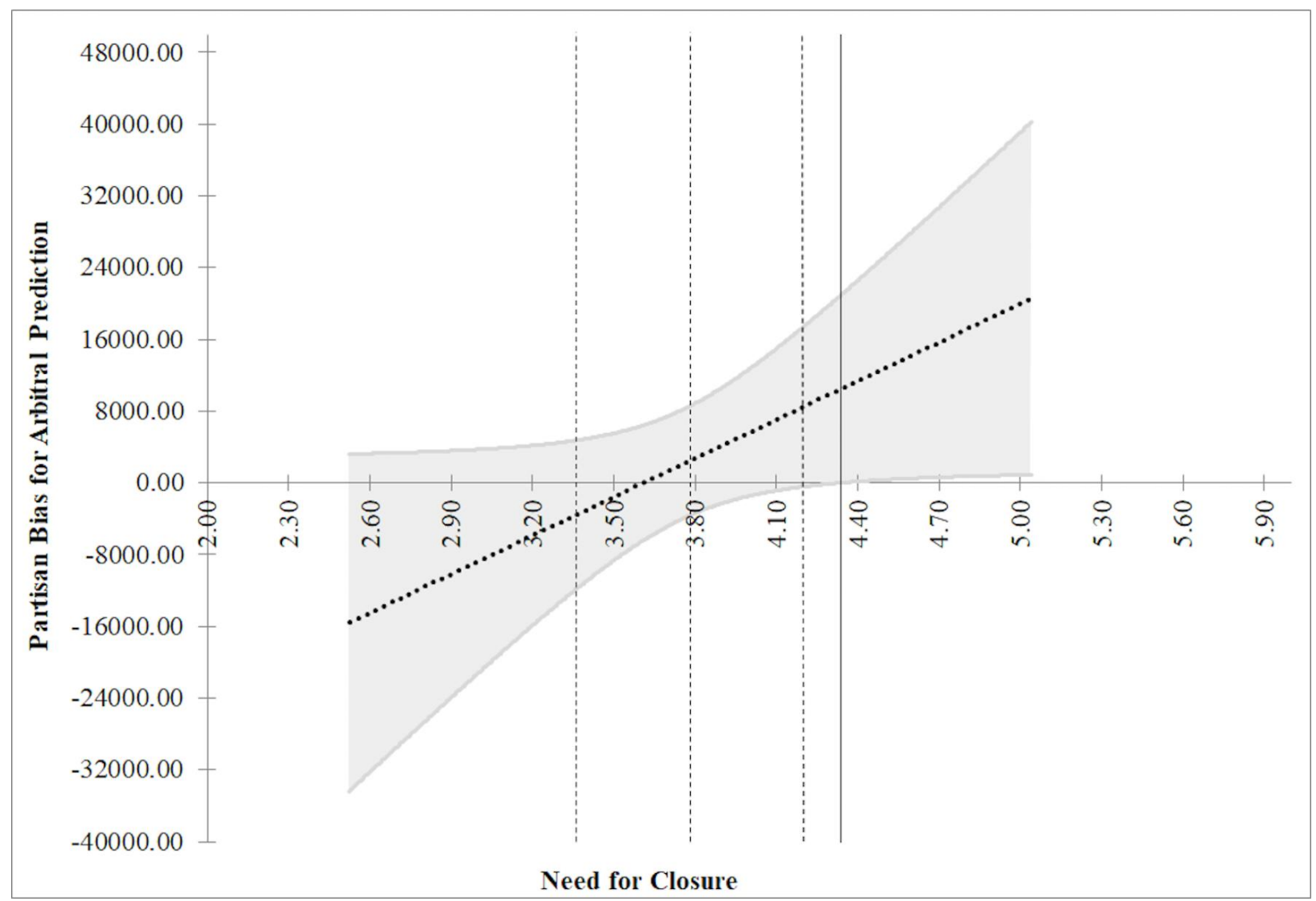

Figure 3. Partisan bias for arbitral predictions predicted from individuals' NFC scores. The solid line indicates the critical value of NFC above which the partisan bias becomes significant. The middle, left and right dashed lines indicate the mean values of NFC and 1SD below and above the mean, respectively. The gray bands represent the $95 \%$ confidence intervals. 


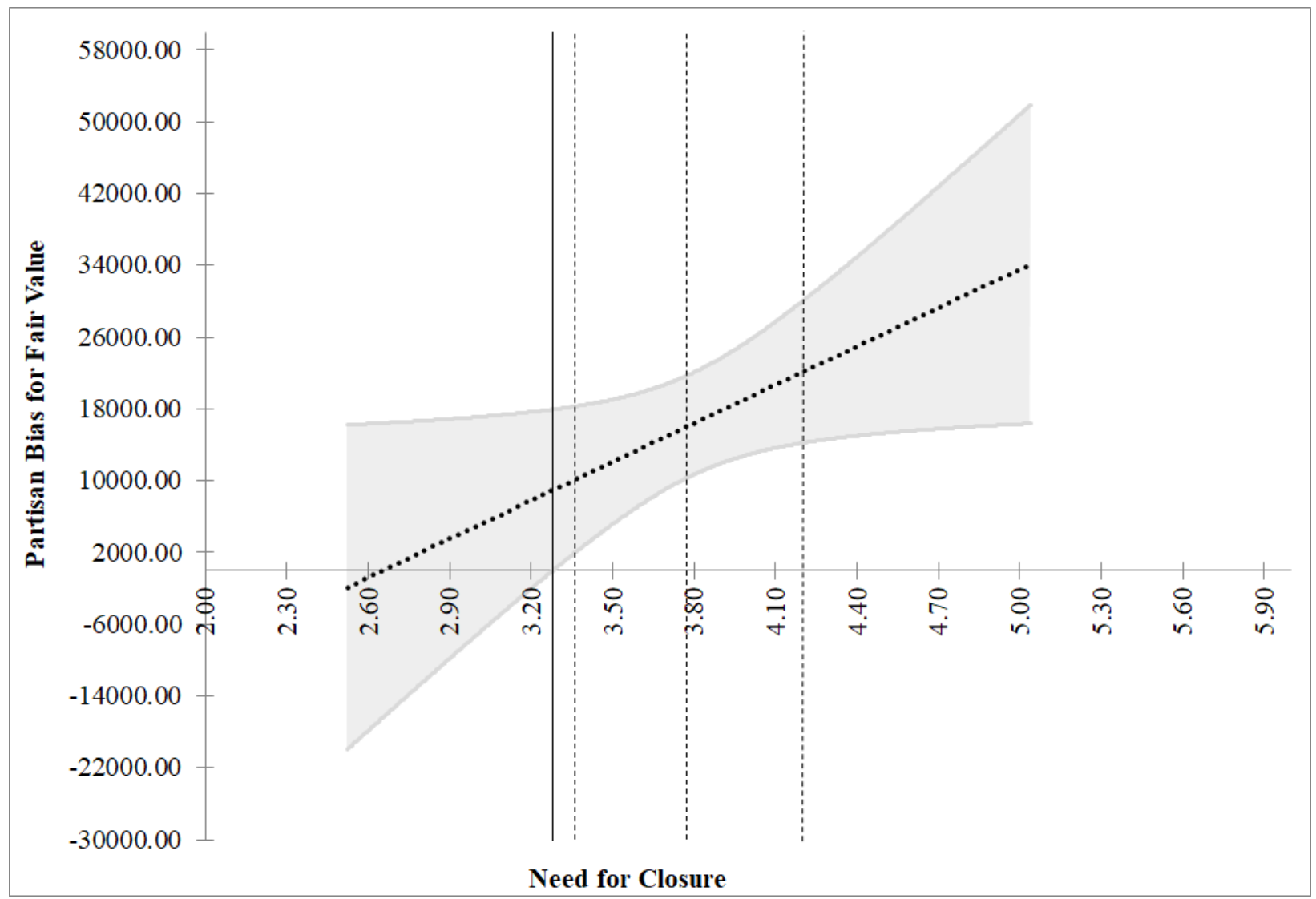

Figure 4. Partisan bias for fair value predicted from individuals' NFC scores. The solid line indicates the critical value of NFC above which the partisan bias becomes significant. The middle, left and right dashed lines indicate the mean values of NFC and 1SD below and above the mean, respectively. The gray bands represent the $95 \%$ confidence intervals.

For each graph in Figures 2 through 4, "critical value" signifies the NFC score threshhold at which partisan role bias began to become significant. As can generally be seen from these figures, the moderating effect of NFC scores on students' susceptibility to partisan role bias was similar for all three methods of case valuation, given that the slopes of the three graphs are all basically the same. However, in each figure, the effect of students' need for closure scores on partisan bias became statistically significant at a different point on the graph.

In Figure 2, "overall \$value" again represents students' mean estimates of the value of Platt $v$. Dixon, averaging their predictions of the most likely arbitral award and their assessments of the case's fair settlement value. When utilizing this valuation method, the effect of individual NFC scores on students' case valuations became significant just above the midpoint of the NFC 6-point scale - at 3.56. In our sample, more than $70 \%$ of participants registered NFC scores at or above this point.

Again, however, when we disaggregated students' arbitral predictions (Figure 3) from their estimates of fair settlement value (Figure 4), different patterns emerged. Recall that we found no statistically significant bias in students' arbitral predictions based on their assigned role: on average, students appeared to be able to predict without bias how a judge might decide a factually ambiguous case. Figure 3 is consistent with this finding, showing that only 
$14 \%$ of students in our sample-those with very high NFC scores (at or above 4.24) -exhibited partisan bias in their arbitral predictions.

Figure 4 is also consistent with our earlier findings and reveals the converse effect: Because most students in our sample exhibited partisan role bias in their fair settlement assessments, only students with low NFC scores ( 3.28 or lower, constituting only $11.32 \%$ of our sample) were able to avoid such self-serving bias.

\section{E. Hypothesis 3: Effects of CTO De-biasing Prompts on Case Valuations}

As described earlier, plaintiff and defendant attorneys assigned to the de-biasing condition in our study were asked to generate and list potential weaknesses of their case. Because they worked on their own, without supervision, we read their responses with some care to try to determine how seriously they approached this task. Overall, our assessment is that most participants took the instruction seriously and generally listed sensible reasons why their client's case might be questionable, regarding both proof of liability and damages. ${ }^{56}$ On the defendant attorney side, for example, one student wrote: "Defendant's inability to remember [much of anything] undermines his stance that he was not impaired by the drinks he'd had that day." On the plaintiff attorney's side, one student noted: "The plaintiff did not get medical help at the scene of the accident and didn't go to a doctor until months later." The great majority of participants listed more than one case weakness; some listed as many as four or five.

How well did the de-biasing prompt work? Contrary to our expectations, it had different effects depending on the case valuation method (see Figures 5 \& 6).

\footnotetext{
56 One exception to this was students' tendency to assume that plaintiff's and defendant's previous traffic citations would be admissible in court as "habit evidence" -- a legally dubious conclusion. See, e.g., Waldon v. City of Longview, 855 S.W. 2d 875, 879-80 (Tex. Ct. App 1993) (defendant police officer's three prior accidents insufficient to constitute a habit). Nevertheless this is an understandable mistake, given that most subjects had not taken or completed a course in Evidence.
} 
Representative Lawyering Bias and Need for Closure

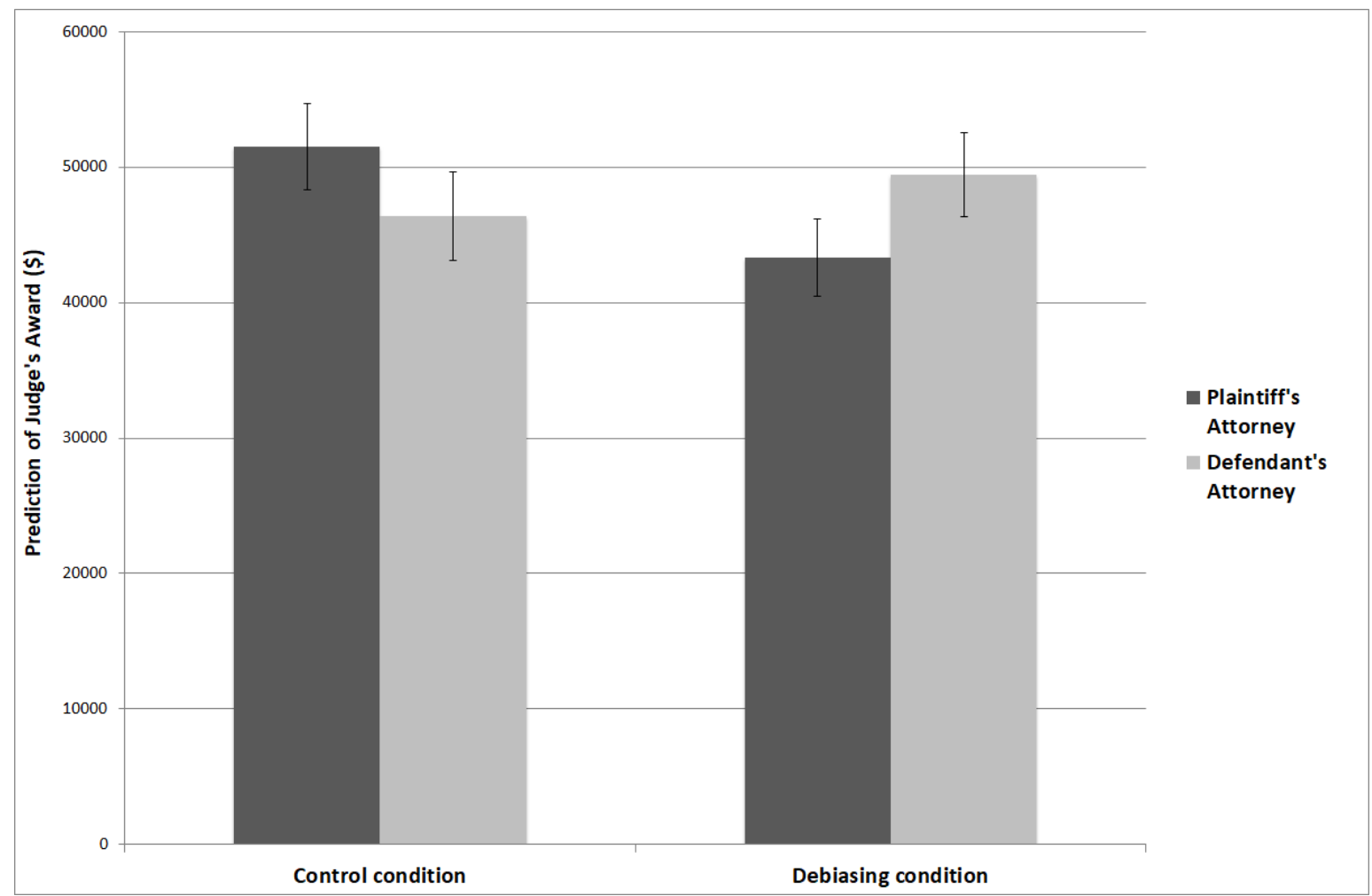

Figure 5. Mean estimates of judge's award (arbitral predictions) by assigned role (plaintiff attorney vs. defendant attorney) by the de-biasing condition (control vs. de-biasing). The error bars indicate standard errors.

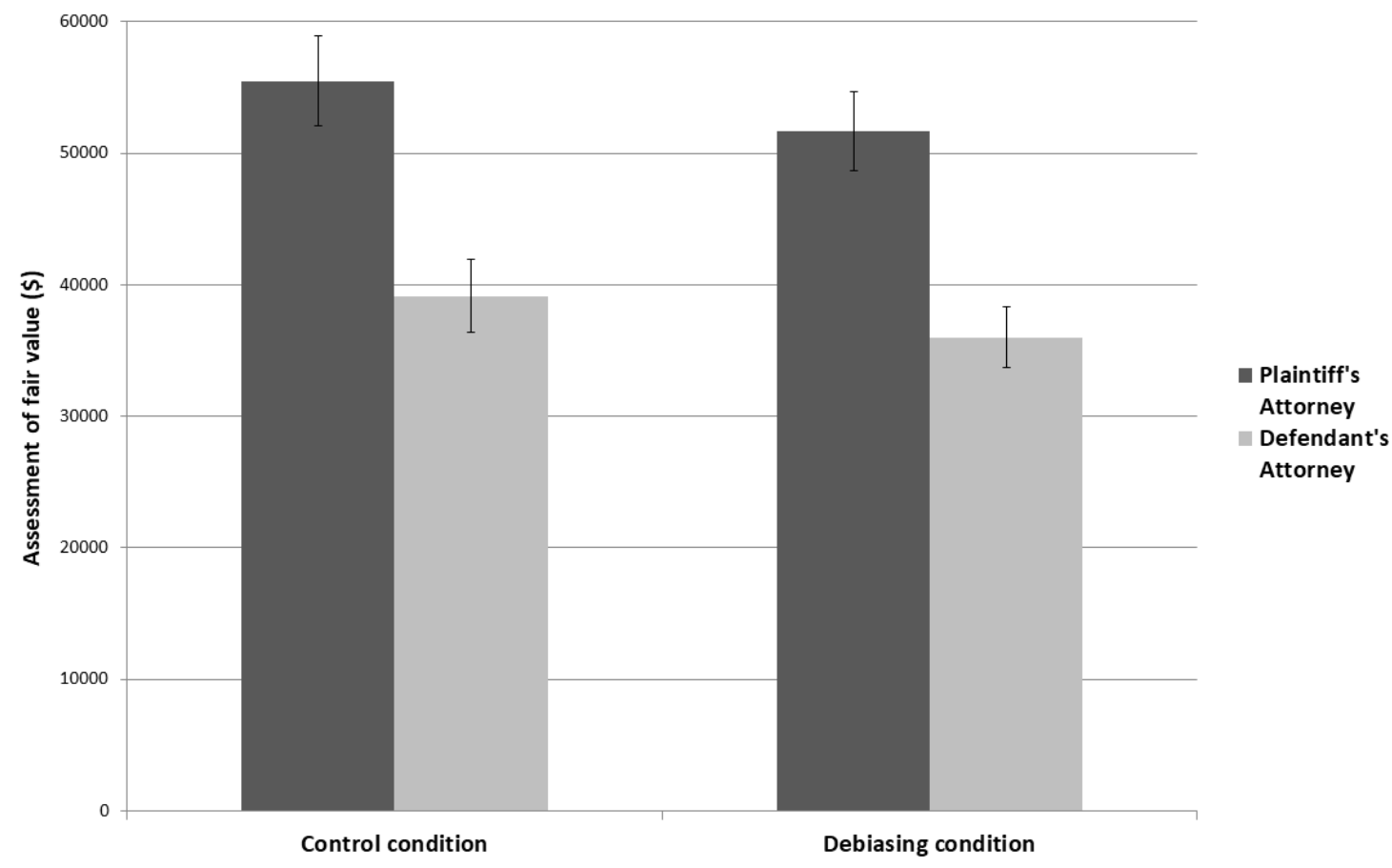


Figure 6. Mean estimates of fair value by assigned role (plaintiff attorney vs. defendant attorney) by the debiasing condition (control vs. de-biasing). The error bars indicate standard errors.

As was reported earlier, in the control condition $(n=232)$, partisan role bias was marginally demonstrated by subjects in their arbitral predictions and significantly demonstrated in their assessments of fair settlement value. As can be seen from comparing Figures 5 and 6 , the de-biasing prompt $(\mathrm{n}=236)$ effectively eliminated partisan bias regarding participants' arbitral predictions only, $M_{\text {plaintiff-defendant }}=-\$ 3,065$, se $=4,244, p=.51$, $d=-0.09$ and not regarding their assessments of fair settlement value, $M_{\text {plaintiff-defendant }}=$ $\$ 15,684$, se $=3,788, t=3.77, p<.001, d=0.54$. The three-way Role $\mathrm{x}$ De-biasing condition $\mathrm{x}$ Case valuation interaction was significant, $t(460)=2.33, p=.021$. These results may suggest that consider-the-opposite de-biasing prompts reduce self-serving biases when aspiring lawyers are called upon to make an objective valuation-predicting what a neutral, impartial judge would award in arbitration, but not when they are called upon to make a subjective evaluation—stating what settlement amount, in their opinion, would be "fair."57

\section{F. Hypothesis 4: Effects of NFC on Susceptibility to De-Biasing Prompts}

Finally, importantly, and also contrary to our expectations, we did not find any statistically significant differences ( $p=.63$ ) between high- and low-NFC individuals in their receptivity to de-biasing prompts. While this lack of effect could be attributable to insufficient statistical power or some other design problem, it appears that high-NFC law students are as open as low-NFC students to de-biasing strategies designed to reduce partisanship in a representative role. These findings may suggest that, while high-NFC students have a motivational preference for certainty and closure over ambiguity, they have the cognitive capacity to entertain ambiguity when prompted to do so.

\section{DISCUSSION}

Our study is subject to a number of obvious limitations. First, as previously noted, we altered several important features from the studies we replicated, complicating the task of teasing out firm conclusions about the reasons why some of our results differed from those of the studies we replicated. In addition, our sample of participating law students, although reasonably diverse in terms of geography and demographics, was not randomly selected and may or may not be representative of experienced lawyers working on actual cases, with real clients and often high-stakes consequences.

The fact that the survey was administered online, in non-laboratory conditions without direct faculty supervision, also presents questions. While the great majority of participants completed the assignment within the suggested 45-minute timeline, a few completed it faster and a few completed it intermittently over the course of several days. This raises

\footnotetext{
${ }^{57}$ It is impossible to compare these results to those of Babcock et al., supra note 32, because the researchers in that study reported the effects of their consider-the-opposite de-biasing prompts on participants' arbitral predictions only. In addition, as described supra Part I.E, we modified the CTO prompt used in that study, confounding the possibility of any direct comparisons.
} 
questions about the level of attention given to the exercise by participants and whether they consulted with other students regarding their case valuations, rather than working alone. ${ }^{58}$ On the other hand, the online administration of our survey may also have increased the "noisiness" of our data, which should have lowered our odds of obtaining significant results. The fact that we managed to obtain significant effects despite these obstacles makes us suspect that the real effects might be larger.

These questions and limitations aside, the present study helps us understand the workings of partisan role bias on a more granular level than previous studies have done, across several dimensions.

\section{A. Need for Closure, Partisan Role Bias and De-Biasing Predictive Judgments}

First, taken as a whole, and consistent with our main hypothesis, our data suggest that the partisan role bias previously reported in studies of real and simulated lawyering behavior cannot be attributed to lawyers and law students generally, but is rather moderated by individuals' need for cognitive closure. The greater a law student's need for closure, the greater the risk that he or she will be influenced by self-serving biases in a representative role. Partisan role bias, it is thus not surprising to find, exists along a continuum. Some students are highly prone to engage in self-serving and/or one-sided thinking, many students are somewhat prone to do so, and some students may in fact be under-confident about their cases and/or too eager to see the other side's point of view. A simple-toadminister motivational scale exists that seems to predict individual students' degree of susceptibility to judgmental role biases with a fair degree of accuracy.

Second, despite the fact that we weakened the de-biasing consider-the-opposite prompt from the one used in the precursor studies, we found that all law students-even high-NFC students-- could be prompted to be less biased-at least in their predictive judgments.

Taken together, these two findings have considerable potential significance for how law schools train their students to assume the role of lawyer. If we want students to be able to overcome their cognitive and motivational biases--as well as the bias "blind spot" that affects all of us ${ }^{59}$-- we must help them understand the degree to which they are susceptible to selfserving biases in the first place. Students preparing for a lifetime of representative lawyering cannot intuitively know where they fall on this spectrum. If administered in the classroom, especially in conjunction with simulated lawyering exercises like the one used in this study, the NFC Scale holds the promise of helping students better understand their own tendencies toward self-serving bias in a representative lawyering role.

Moreover, the success of our consider-the-opposite prompt in de-biasing even high-NFC students' arbitral predictions suggests that with proper instruction and practice, all law students can not only learn about their potential susceptibility to role bias in their legal predictions, but also can take effective steps to reduce bias in their predictive judgments by regularly practicing modes of counter-attitudinal thinking.

\footnotetext{
${ }^{58}$ For a summary of the risks and benefits of another online research platform comparable to Qualtrics, see Michael D. Buhrmester, et al., An Evaluation of Amazon's Mechanical Turk, Its Rapid Rise, and Its Effective Use, 13 (2) PERSPS. ON PSYCHOL. SCI. 149, 151 (2018). (Noting that some studies have shown that online participants' attention is better than the attention of undergraduates in comparable in-class experiments.)

${ }^{59}$ Pronin et al., PERSONALITY \& Soc. Psychol. BulL., supra note 17.
} 


\section{B. Predictive Judgments versus Fairness Assessments}

Next, our results suggest that "partisan role bias" may not be a unitary phenomenon as previously assumed in studies of lawyering judgment, but rather may consist of predictive judgments and fairness assessments operating independently of one another. As described earlier, previous empirical studies have consistently found that agents (including lawyers) are affected by partisan role biases when they assume a representative role. 60 But no previous studies have attempted to draw as clear a demarcation as our study did between predictions of the most likely judicial outcome in a case on the one hand, and more subjective assessments of its "fair settlement value" on the other.

The standard economic theory of bargaining suggests that there ought to be little difference between lawyers' predictions of the most likely judicial outcome in a case on the one hand, and their advice to clients about what constitutes a "fair settlement" on the other. Negotiation instructors commonly teach their students how to determine the "expected value" of a disputed claim, by objectively evaluating the approximate odds of winning the case, determining the most likely damage award, and deducting the costs of an expected trial. ${ }^{61}$ Indeed, the authors of the 1993 and 1998 Experiments seem to have assumed that survey students' arbitral predictions and fair settlement assessments would be roughly the same. Writing in 1995, they commented, "Even when parties have the same information, they will come to different conclusions about what a fair settlement would be and base their predictions of judicial behavior on their own views of what is 'fair."'62

Our findings suggest that this assumption may not have been correct. Although students' arbitral predictions were only marginally affected by their assignment to the role of plaintiff's or defendant's counsel, their fairness assessments were, on average, highly influenced by their role assignment. When participants were prompted to distinguish their own assessments of a fair settlement value for Platt $v$. Dixon from their predictions of the judge's most likely arbitral award, the difference between plaintiffs' lawyers' and defendants' lawyers' fair settlement value assessments was double the difference between the two groups' arbitral predictions.

The large gap we found in plaintiff attorney and defendant attorney assessments of the fair settlement value of the case is surprising when one takes into account the quotidian nature of the Platt $v$. Dixon simulation. While one might expect fairness considerations to play a significant role in partisan assessments of cases involving claims of deliberate misconduct (e.g., discrimination, fraud, assault and the like), or difficult relational claims (e.g., high conflict divorce cases, messy partnership dissolutions or workplace disputes), the case under study was an online simulation of an everyday car accident case between strangers. A simple car accident case is not the sort of matter likely to produce controversy about the fairness of the governing legal rules. ("The principles of negligence may require that result, but I think it's unfair!") While it is true that the case file presented some contested

\footnotetext{
60 See supra Part I.A.

61 See, e.g., Peter Toll Hoffman, Valuation of Cases for Settlement: Theory and Practice. 1991 J. DISP. RESOL. 1 (1991); Nancy A. Welsh, Fairness: Perceptions of Fairness in Negotiation, 87 MARQ. L. REV. 753, 760 (2004).

${ }^{62}$ Linda Babcock, et al, Biased Judgments of Fairness in Bargaining, 85 AM. ECoN. REV., 1337, 1337 (1995) (emphasis added).
} 
evidence of drunk driving on the part of the defendant, as well as a perhaps exaggerated damage claim by the plaintiff, we would not have predicted such a strong "fairness" reaction on the part of respondents to these materials.

Nonetheless, these results are potentially significant in light of the 1993 Experiment's finding that differences in fair settlement value assessments within negotiation pairs were even better predictors of bargaining impasse than comparable differences in bargainers' arbitral predictions. We know from highly stylized experiments like the "Ultimatum Game" that perceptions of unfair conduct by one negotiator can cause an opposing negotiator to make objectively irrational decisions. ${ }^{63}$ We would hypothesize that clashing fairness norms may play an even greater role with practicing lawyers-who have real clients, real adversaries and negotiate for real stakes - than they would play in any online simulation involving law students. The field would benefit from additional empirical research on how objective determinations of case value and subjective fairness assessments combine to affect lawyers in their actual negotiations and client counseling.

\section{De-Biasing Fairness Assessments}

Next, while the "consider-the-opposite" de-biasing prompt we gave students was effective in de-biasing their arbitral predictions, it was not effective in de-biasing their fairness assessments. How does one explain this finding and what are its possible implications?

In retrospect, this result is perhaps not surprising. Previous research suggests that consider-the-opposite prompts are primarily effective in de-biasing judgments involved in objective and predictive tasks such as assessing the evidence regarding the effectiveness of capital punishment in deterring crime ${ }^{64}$ or deciding whether or not to fly the Space Shuttle Challenger mission under specified simulated weather conditions. ${ }^{65}$ Research suggests that a different de-biasing strategy-perspective-taking, i.e., the attempt to prompt people to consider and articulate how the world looks to others-is more effective in mitigating egocentric judgments about what is "fair" in social or competitive settings. Perspectivetaking prompts have been shown, for example, to reduce egocentric biases in individuals' views about what is fair pay for themselves versus others on an assigned work task, 66 their perspectives about the relative value of their own contributions to a group project, ${ }^{67}$ and their views about what is a fair allotment of resources in settings where limited resources must be divided. 68

In legal dispute settings, a perspective-taking intervention might, for example, ask a disputant or his lawyer to "step into the shoes" of the opposing party, for example by considering how the opponent's actions might have a different and more innocent

\footnotetext{
${ }^{63}$ Richard H. Thaler, Anomalies: The Ultimatum Game, 2 J. Econ. PerSP. 195, 197 (1988).

${ }^{64}$ Lord et al., supra note 18.

65 Kray \& Galinsky, supra note 24.

${ }^{66}$ David M. Messick \& Keith Sentis, Fairness, Preference, and Fairness Biases, in Equity Theory: Psychological AND Sociological PerSPeCtives 61 (David M. Messick \& Karen S. Cook eds., 2006).

67 Kenneth Savitsky et al., The Unpacking Effect in Allocations of Responsibility for Group Tasks, $41 \mathrm{~J}$. EXPERIMENTAL SOC. PSYCHOL. 447 (2004).

68 Nicholas Epley et al., When Perspective Taking Increases Taking: Reactive Egoism in Social Interaction, $91 \mathrm{~J}$. PERSONALITY \& SOC. PSYCHOL. 872 (2006).
} 
explanation. ("From Plaintiff Platt's perspective, can you think of some other reason, other than that he was inventing his injuries, why he might have waited two months to consult a doctor?") We did not attempt a manipulation of this kind because it was not part of the studies that we were replicating.

Explicit training in taking the perspective of an opponent is not a standard a part of the law school curriculum to nearly the same degree as is the training that requires students to read judicial opinions and take the perspective of a neutral judge. Nor is "fairness" typically much discussed in the law school classroom, particularly the kind of subjective fairness norms that can strongly affect people in conflict. Further research is needed to determine the extent to which perspective-taking prompts reduce self-serving assessments of fairness in a representative lawyering role, and, if effective, what steps law schools might take to increase such training as part of their standard curricula.

\section{Lack of Significant Bias in Students' Arbitral Predictions}

Finally, recall the findings of the earlier studies under replication-that students were significantly biased in both their arbitral predictions and fair settlement value assessments. By contrast, when we asked our student participants to distinguish their predictions of what a judge most likely would award the plaintiff Platt in arbitration from what settlement outcome in the case "irrespective of the arbitral award" they would consider "fair," we found that their arbitral predictions were only marginally affected by their role assignment as plaintiff's or defendant's attorney, but their fair value assessments were highly affected by them.

How does one explain these differing arbitral results? As one possibility, it may be that when students assume the role of lawyer-representatives, they are somewhat less susceptible to predictive biases than when assigned to the role of principals, because of the greater distance and objectivity inherent in that role.69 This explanation has a surface plausibility and is also consistent with our data, as we found smaller mean differences between the plaintiff and defendant lawyers' valuations than the mean differences between the parties' valuations obtained in the previous studies. On the other hand, if representatives are really less susceptible than principals to predictive bias, how does one explain the persistence of significant partisan bias that we found in students' fair settlement value assessments?

A second, more likely explanation for our differing arbitral results is that the law students in our sample, by dint of their training and experience reading judicial decisions, were better able than the non-law students in the two previous studies to take external reality constraints into account when predicting how a judge might rule in a factually ambiguous case. In a well-known book, former Yale Law School Dean Anthony Kronman argued that the case method of instruction, used in every U.S. law school, instills in students the ability to "suppress all sympathies in favor of a judge's scrupulous neutrality" and helps them make more accurate predictions about judicial outcomes and other uncertain legal events. ${ }^{70}$ According to this hypothesis, after one or two or three years of reading appellate decisions and taking a judicial perspective, the law students in our sample would have been better able

69 Jason Dana \& Daylian M. Cain, Advice Versus Choice, 6 Current Op. PsYChol. 173 (2015).

70 Anthony T. Kronman, The Lost LAWYer: FaILIng IdeAls of The Legal Profession 113, 122-28 (1993). 
than the non-law students in the previous studies to reason to themselves, "I may think that this case is worth [X], but judges are unpredictable, and who knows what this judge might do."

But this explanation has difficulties as well. The 1993 Experiment included eighty law students in its sample. The researchers found no statistically significant differences between their responses and the responses of the eighty undergraduates also in their sample, and accordingly aggregated their responses in their analysis. ${ }^{71}$ (The 1998 Experiment utilized MBA students exclusively.)

Our finding that law students were only marginally biased in their predictions of future judicial outcomes could therefore benefit from further replication. For example, the 1993 Experiment did not indicate whether the law students in its sample were comprised of firstyear students only, or a combination of first-year and upper-division students, as in our study. It seems likely that law students improve in their ability to make dispassionate judicial predictions as they progress through their legal studies. Previous researchers have attempted to investigate how novice and experienced medical students' diagnostic skills improve over time and are affected by their need for cognitive closure. ${ }^{72}$ Similar experiments could be designed to attempt to document improvements in first, second and third year law students' ability to make objective predictions.

\section{CONCLUSION}

Representative lawyers are valued, in part, for the accuracy and objectivity of the advice they provide their clients. Partisanship and zeal are of course expected of lawyers as well, but partisanship may poorly serve a client's interests if the lawyer's advice is distorted by biases of which he or she is unaware. The present study underscores the importance of teaching law students to be self-aware about the unconscious biases that may cloud their judgment when they begin to take on a representative lawyering role. It provides a method for testing students' susceptibility to judgmental bias on an individual basis. And it provides supporting evidence for earlier studies that demonstrate the value of counter-attitudinal thinking as a de-biasing strategy for improving predictive judgment.

This kind of self-knowledge and training is important for all law students who, as prospective representative attorneys, will soon be making predictions and giving advice to clients. But no matter what students do with their law degrees after they graduate, they can potentially play a vital social role in improving the quality of discourse on controversial public issues to the extent that they are able to model flexible, nuanced thinking and openness to opposing points of view. Viewed from that broader perspective, the kind of training described in this article might well be included in every law school curriculum.

The current study leaves unresolved a number of important questions: Do law students improve in their ability to make objective legal predictions as they proceed through law school? If so, by how much, and is this improvement moderated by their need for closure? Legal predictions aside, to what extent are lawyers influenced by considerations of fairness when advising their clients about potential courses of action? In what kinds of contexts does this occur, and with what effects? American legal education is sometimes criticized for doing

71 Loewenstein et al., supra note 11 , at 149.

72 Roets et al., supra note 39. 
a credible job of preparing students to make predictions about future legal outcomes, by applying legal rules to a set of facts, but a less-than-optimal job in preparing students for the more subjective, affective aspects of law practice, in which strong feelings and hostile attributions often hold sway, and clashing norms of "fairness" compete with one another. ${ }^{73}$ What, if anything, can law schools do to improve in this dimension? Questions such as these would benefit from further investigation. Beyond this, the need for cognitive closure may provide a heretofore unexplored and useful conceptual frame for examining the decision making of other key actors in the legal system-practicing attorneys, judges and juries.

${ }_{73}$ Jane H. Aiken, Striving to Teach "Justice, Fairness and Morality," 4 CuInICAL L. Rev. 1, 6-10 (1997); Frenkel \& Stark, supra note 5, at 53-58. 


\section{ApPendix: Need for Cognitive Closure SCale (Webster \& Kruglanski, 1994)}

Please answer the following questions about yourself:

1. I think that having clear rules and order at work is essential for success.

123456

Strongly Disagree Strongly Agree

2. Even after I've made up my mind about something, I am always eager to consider a different opinion.

123456

Strongly Disagree Strongly Agree

3. I don't like situations that are uncertain.

123456

Strongly Disagree Strongly Agree

4. I dislike questions which could be answered in many different ways.

123456

Strongly Disagree Strongly Agree

5. I like to have friends who are unpredictable.

123456

Strongly Disagree Strongly Agree

6. I find that a well ordered life with regular hours suits my temperament.

123456

Strongly Disagree Strongly Agree

7. When dining out, I like to go to places where I have been before so that I know what to expect.

123456

Strongly Disagree Strongly Agree

8. I feel uncomfortable when I don't understand the reason why an event occurred in my life. 123456

Strongly Disagree Strongly Agree

9. I feel irritated when one person disagrees with what everyone else in a group believes.

123456

Strongly Disagree Strongly Agree

10. I hate to change my plans at the last minute.

123456

Strongly Disagree Strongly Agree 
11. I don't like to go into a situation without knowing what I can expect from it. 123456

Strongly Disagree Strongly Agree

12. When I go shopping, I have difficulty deciding exactly what it is that I want. 123456

Strongly Disagree Strongly Agree

13. When faced with a problem I usually see the one best solution very quickly. 123456

Strongly Disagree Strongly Agree

14. When I am confused about an important issue, I feel very upset.

123456

Strongly Disagree Strongly Agree

15. I tend to put off making important decisions until the last possible moment. 123456

Strongly Disagree Strongly Agree

16. I usually make important decisions quickly and confidently.

123456

Strongly Disagree Strongly Agree

17. I would describe myself as indecisive.

123456

Strongly Disagree Strongly Agree

18. I think it is fun to change my plans at the last moment.

123456

Strongly Disagree Strongly Agree

19. I enjoy the uncertainty of going into a new situation without knowing what might happen.

123456

Strongly Disagree Strongly Agree

20. My personal space is usually messy and disorganized.

123456

Strongly Disagree Strongly Agree

21. In most social conflicts, I can easily see which side is right and which is wrong.

123456

Strongly Disagree Strongly Agree

22. I tend to struggle with most decisions.

123456 
Strongly Disagree Strongly Agree

23. I believe that orderliness and organization are among the most important characteristics of a good student.

123456

Strongly Disagree Strongly Agree

24. When considering most conflict situations, I can usually see how both sides could be right.

123456

Strongly Disagree Strongly Agree

25. I don't like to be with people who are capable of unexpected actions.

123456

Strongly Disagree Strongly Agree

26. I prefer to socialize with familiar friends because I know what to expect from them.

123456

Strongly Disagree Strongly Agree

27. I think that I would learn best in a class that lacks clearly stated objectives and requirements.

123456

Strongly Disagree Strongly Agree

28. When thinking about a problem, I consider as many different opinions on the issue as possible.

123456

Strongly Disagree Strongly Agree

29. I like to know what people are thinking all the time.

123456

Strongly Disagree Strongly Agree

30. I dislike it when a person's statement could mean many different things.

123456

Strongly Disagree Strongly Agree

31. It's annoying to listen to someone who cannot seem to make up his or her mind.

123456

Strongly Disagree Strongly Agree

32. I find that establishing a consistent routine enables me to enjoy life more.

123456

Strongly Disagree Strongly Agree 
33. I enjoy having a clear and structured mode of life.

\section{6}

Strongly Disagree Strongly Agree

34. I prefer interacting with people whose opinions are very different from my own.

123456

Strongly Disagree Strongly Agree

35. I like to have a place for everything and everything in its place.

123456

Strongly Disagree Strongly Agree

36. I feel uncomfortable when someone's meaning or intention is unclear to me.

123456

Strongly Disagree Strongly Agree

37. When trying to solve a problem I often see so many possible options that it's confusing. 123456

Strongly Disagree Strongly Agree

38. I always see many possible solutions to problems I face.

123456

Strongly Disagree Strongly Agree

39. I'd rather know bad news than stay in a state of uncertainty.

123456

Strongly Disagree Strongly Agree

40. I do not usually consult many different opinions before forming my own view.

123456

Strongly Disagree Strongly Agree

41. I dislike unpredictable situations.

123456

Strongly Disagree Strongly Agree

42. I dislike the routine aspects of my work (studies).

123456

Strongly Disagree Strongly Agree 